\title{
The Healing Power of Storytelling: Finding Identity Through Narrative
}

\author{
Seren Friskie* \\ Douglas College \\ serenitymichealfriskie@gmail.com
}

\begin{abstract}
This paper describes the power of storytelling in the context of an Indigenous youth collective, which gathers each week to share their lived experiences and learn song, dance, and lessons through story. I begin with my own life narrative followed by an exploration of how the intergenerational transmission of historical trauma has left many Indigenous youth searching for a connection to their culture. I then discuss research that reveals the importance of cultural continuity, self-determination, and engagement in the community to the healing journey of Indigenous youth. Next, I consider oral storytelling as one method of knowledge delivery, utilized by Indigenous Nations for thousands of years, that seamlessly blends cultural learning and thus connection to identity. I detail the creation of a Youth Storytelling Circle which centres teachings from the Stó:lō, Haida, Nisga'a, Salish, and Popkum Coast Salish Nations surrounding the shores and rainforests of what is now British Columbia. I conclude with reasons why engaging youth in their wellbeing through traditional practices is of high importance to us all as Indigenous community members.
\end{abstract}

Keywords: intergenerational trauma; healing; storytelling; narrative identity; Indigenous knowledge

"If the legends fall silent, who will teach the children of our ways?" (George, 1974, p. 54)

$\mathrm{O}$ ral storytelling is a collective enterprise, in which communities are supported, cultures are unified, and identities are formed. There is a power for the individual, and for society, more generally, when stories are shared, and thus knowledge is passed from one to another. Narrative has been used within the field of counselling as a tool to facilitate the healing process for those who are living with trauma (Archibald, 2008). For many of these individuals, sharing their own experiences in the form of personal narrative or story can bring new awareness and a sense of clarity to painful memories. Sharing and interpreting experiences bridges cultural, linguistic, age, and other divides (Corntassel, Chaw-win-is, \& T'lakwadzi, 2009). For thousands of years, Indigenous Peoples have relied on personal narrative and oral storytelling for the intergenerational transmission of knowledge and culture, reflecting the strength of our people and the resilience of our ancestors (Corntassel et al., 2009). Storytelling has been used as a sacred method to teach ethics and values, and oral histories allow us to connect ourselves to the past of our ancestors.

*I begin by acknowledging that this work took place on the traditional and ancestral territories of the Coast Salish Peoples, including the Musqueam, Tsleil-Waututh, Squamish, and Stó:lô. I thank these strong Nations for allowing myself and others the daily privilege of enjoying these lands and their sacred teachings, and for their strength and resilience. I would like to thank my supervisor, Dr. Lisa Smith (Douglas College), for providing me with endless support and mentorship. I also thank Dr. Carla Hotel and Dr. Karyn Audet for their support and contributions to my learning experiences. And finally, I would like to thank Steven Bishop for providing me with the opportunity to write this paper and speak on a topic affecting Indigenous Peoples across Canada. 
The strength of oral storytelling for Indigenous Nations dates back thousands of years, and the people who hold those stories have overcome many barriers, such as the assimilation tactics of colonization that sought to destroy them. First Nations, Métis, and Inuit communities have utilized the power of storytelling to pass knowledge from one generation to the next. Societies have counted on the transmission of oral histories, lessons, and traditions to preserve historical records and nourish shared identity (Ward, Branch, \& Fridkin, 2016). The concept of narrative identity theorizes that individuals form an identity by integrating their life experience into an internalised, evolving story of the self that provides them with a sense of unity and purpose in life (Kirmayer, Simpson, \& Cargo, 2003). This life narrative incorporates one's reconstructed past, perceived present, and imagined future. For this reason, to continue this traditional practice with youth is in itself an act of reclamation and activism, as we reclaim this practice for generations to come.

This paper describes the power of storytelling in the context of an Indigenous youth collective, which gathers each week to share lived experiences and learn song, dance, and lessons through story. I share my own life narrative, followed by an exploration of how the intergenerational transmission of historical trauma has impacted Indigenous youths' connections to their culture. I then discuss research which reveals the importance of cultural continuity, self-determination, and engagement in the community to the healing journey of Indigenous youth. Next, I consider oral storytelling in the context of the Indigenous youth collective, which has impacted the lives of over sixty Indigenous youth. The teachings of the collective come from the Stó:lō, Haida, Nisga'a, Salish, and Popkum Coast Salish Nations surrounding the shores and rainforests of what is now British Columbia. The work of the collective includes reconnecting with family, learning traditional cedar weaving, incorporating ceremony in our lives, and the creation of other groups throughout the Lower Mainland of British Columbia. The conclusion of this paper reflects the need for bridging the divide between our public institutions of health and the gift of knowledge from Elders, youth, and Indigenous Nations.

\section{Recapturing My History Through Cultural Connection}

Stories, as we know them in Western popular culture, tend to be linear, starting with a foundation of people, places, and things, but in reality our own stories are nonlinear in nature. They blend memories, reflections, and pieces of ourselves caught in time. Here you will read a small fragment of my story. Growing up, I always knew I was Indigenous, with blood from various strong Nations, including Chehalis and Cree. All my relations rest with the Sts'Ailes and Stó:lō People, and I take strength from the memory and histories of my ancestors. I wish I could say that this was always the case. In the past, my family's Indigenous identity was more of a shameful distinction about us, rather than a place to gain strength from our ancestors.

The Canadian Federal Government established the Indian Act in 1876, which stripped my grandmother of her Indigenous heritage when she married a non-Indigenous man. My grandmother was a child of the residential school system, and was adopted into a white family, which caused deep identity strain. My own father was absent in my early childhood, and sadly died in my early teens. He could not teach me about our traditional customs and stories. This lost sense of identity, coupled with trauma, remained with me throughout my youth. I craved a piece of myself that I had not yet found. I came to understand that this missing piece was what our colonizers tried to take away: our voice and our history.

I began to notice the same problems I was dealing with in the lives of other young people around me. After I graduated from high school, I became an Indigenous Youth Counselor within my Nation and local Friendship Center, where I joined in on activities every week and was supported physically, emotionally, spiritually, and mentally. This passionate community, which aided in my personal healing, brought me hope and a mission to improve mental health services for Indigenous communities. I share this so that readers can understand me, my intentions, and my craving for story, culture, a place, a home, and an 
identity, which were pieces missing from my own upbringing. When I share my culture now, I feel pride. I feel the strength of my ancestors, I feel their resilience, and I give thanks to those Elders who nourished me to utter the words "I am proud of where I came from."

\section{Historical Trauma and Oppression}

Intergenerational trauma, or historical trauma, has been the focus of many dialogues in academic spaces, but little research has been applied to healing collective trauma within our communities. Many mainstream health services also disregard holistic and traditional Indigenous practices in their service models. Supporting the need for fundamental change in the way health, wellbeing, healing, and culture are viewed, there has been a push to include unconventional or underused knowledge from Indigenous leaders. Intergenerational trauma can have a detrimental effect on Indigenous youth and give way to a misplaced identity and disorientation from community. This lost sense of identity can be traced to the beginning of European contact and colonization, which violently eroded knowledge systems through the theft of land, suppressed languages, and severing of family and community relationships for the Indigenous populations on Turtle Island.

For over five centuries, First Nations, Métis, and Inuit peoples of what is now Canada have experienced disproportionate rates of violence and health disparities (Homicide in Canada, 2014). This collective experience of emotional, physical, mental, and spiritual harm has been passed intergenerationally through a phenomenon known as historical trauma (Gone, 2013; Wesley-Esquimaux \& Smolewski, 2004). Largely a consequence of the residential school system, among other colonizing efforts, historical trauma persists in individuals, families, and communities. The cultural loss, coupled with physical, sexual, and psychological abuse experienced by residential school survivors has embedded itself into the daily lives of not only those who have survived, but also their descendants, thereby touching all Indigenous peoples (Deborah, 2005). This socio-psychological legacy of trauma brings attention to the complex and cumulative nature of the ongoing impact of colonization (Gone, 2013).

The concept of historical oppression is important to understand in relation to the experiences of Indigenous youth. Related to historical trauma, historical oppression includes both bygone and modern forms of oppression (Burnette \& Figley, 2017). The impacts of historical oppression are not solely represented within individuals, but manifest as social, health, and emotional disparities affecting Indigenous identity (Beltrán \& Begun, 2014). These disparities can be health inequalities such as disproportionate rates of diabetes, substance use, and low internal self-esteem in Indigenous Peoples (Witt, 1998). Historical oppression can further be seen in everyday micro-aggressions, poverty, marginalization, and discrimination, all of which have contributed to the outlook Indigenous youth have had on themselves, their community, and their culture (Burnette \& Figley, 2017). Many Indigenous youth experience devastating health and wellness burdens due to historical oppression, and this oppression manifests itself in self-destructive behaviour (O’Keefe, Tucker, Cole, Hollingsworth, \& Wingate, 2018).

\section{Building Academic Research into Community Practice}

Addressing and healing from historical trauma and oppression requires culturally informed practices to support health and wellbeing in Indigenous communities. The past and present research I will discuss in this section affirms what many Indigenous Peoples know through lived experience: connecting to culture, identity, and community, and being able to make voluntary decisions about health and wellbeing, is beneficial to our healing process. For example, research from the Aboriginal Healing Foundation, which was established in 1998 to promote reconciliation and healing practices that address the legacy of colonization, asserts that a set of factors contribute to healing from historical trauma and the renaissance of Aboriginal traditional values (Wesley-Esquimaux \& Smolewski, 2004). These include "the restoration of 
traditional systems of belief and practice; the resurgence and reclamation of languages; the growth of an Aboriginal sense of national identity; and the reconstruction and deconstruction of Indigenous people's history" (Wesley-Esquimaux \& Smolewski, 2004, p. 1). Findings by the Aboriginal Healing Foundation are also reflected in academic research conducted within Canada that seeks to answer questions of how to improve the health and well-being of Indigenous Peoples. These findings include the revelation that healing interventions should be placed within the larger context of the historical experience (Chansonneuve, 2015). Because of its ability to bridge social, generational, and cultural connections, oral storytelling has been highlighted as a key approach to building a healthy and balanced life (Chansonneuve, 2005).

Data on deaths by suicide in British Columbia's 196 First Nations Bands between 1987 and 1992 show that nearly $90 \%$ of Indigenous youth suicides occurred in approximately $10 \%$ of Bands (Chandler $\&$ Lalonde, 1998). In some communities, death by suicide rates were 800 times the national average, while in others death by suicide was nonexistent (Chandler \& Lalonde, 1998). While media coverage typically characterizes First Nations Bands as homogenous, researchers Chandler and Lalonde (1998) utilized six community-level markers of cultural continuity to explain such vast differences in youth deaths by suicide. They found that, in communities that lacked markers of cultural continuity, such as selfgovernance, culturally relevant education, control over health and public services, and cultural facilities, there was a death by a suicide rate of 137.5 per 100,000 peoples (Chandler \& Lalonde, 1998). In contrast, communities with all six markers of cultural continuity reported zero suicides within the five-year study period (Chandler \& Lalonde, 1998). The work pioneered by Chandler and Lalonde affirms that creating opportunities for young people to engage in cultural practices in a community setting is not simply a kind gesture, or a fun social activity, but a matter of life or death.

Research conducted by Howell, Auger, Gomes, Brown, and Leon (2015) explored how traditional Indigenous healing methods can be applied to improve health inequities of the urban Indigenous community. They introduced health circles to Indigenous participants. These health circles were gatherings of Indigenous Peoples who wanted to improve their health through community organization, teaching, and shared knowledge. The participants engaged in drum lessons, traditional food and medicine classes, and the practicing of ceremony. They came together "as one heart, one mind, by listening to the medicine and ancestors through the cultural teachings, to each other, and to all [their] relations" in order to "return to being of good mind, heart, good spirit, and good body" (Howell et al., 2015, p. 117). The results of these circles indicated that these gatherings cultivated a healthy recognition of identity, and also bridged cultural oneness and community through story (Howell et al., 2015).

\section{Origins: How the Youth Storytelling Circle Came to Be}

As a Chehalis and Cree youth, I bore witness to the breakdown of Indigenous identity and connection in my own family and wondered how I could implement a change in direction of how we view our identity as Indigenous. In my own case, two of my grandmothers attended residential school and one grew up within the Canadian foster system. These integral facts about their lives were hidden by my grandmothers from the rest of the family and shrouded in shame. The discovery of this history fueled me with the passion to learn and rekindle our culture within my family. The premature death of my father, who was a prominent figure in Stó:lō First Nation, when I was three years old, also fueled my internal fire to explore my family identity and build a relationship posthumously. The support I was given during this process, and the lessons I learned during my time as a youth counselor, inspired me to implement the Youth Storytelling Circle.

While speaking with one of the Elders in my community, Marianne Blackroe, I visualized a Youth Storytelling Circle. Storytelling was chosen because of its connection to the passage of knowledge, lessons, and cultural learning in a welcoming environment. My process of building the Youth Storytelling Circle was guided by the techniques I learned through trauma informed training and peer support best-practices. 
I also applied the tips I learned in my own healing while seeing an Indigenous counselor, as well as the scholarly research conducted by Indigenous academics I discussed above. Because historical trauma and oppression have persisted in communities as a collective wound experienced by whole Nations, I decided, with input from three Stó:lō Elders through the process of talking circles, that we should heal collectively as well. We believed that storytelling might provide a sense of hope and meaning for people in light of traumatic experiences (Wexler, 2009). The Youth Storytelling Circle would be a space where young people could come together, talk about their families, and create narratives as they felt comfortable. It was also designed to teach us about our own Coast Salish culture through storytelling, which included traditional stories and lessons told to us by an Elder, typically with accompanying drumming and singing.

In Mi'kmaw poet and songwriter Rita Joe's (1989) poem about the loss of her Indigenous language at residential school, she writes, "I lost my talk / The talk you took away...let me find my talk / So I can teach you about me." These particular lines describe the process of cultural destruction. Her "talk" is her language, which is integral to cultural connection. When Indigenous Peoples find their talk, or their language, they can open up a dialogue to share the core pieces of themselves. Indigenous peoples have been searching, re-kindling, and discovering their cultural practices since they were banned. Although many Nations held onto their cultural practices, traditions, and songs, which had to be kept underground, there were others who were separated or assimilated, and who resisted the remoulding tactics by the hands of Eurocentric colonizers (Waldram, 2008). Although assimilation was violently forced upon Indigenous Nations, there was no lack of incredible resistance and resilience to survive and thrive. This resistance and resiliency continues today.

Keeping in mind this abuse of power by the Canadian state, our organizing of the Storytelling Circle was centred on traditional wellness practices that are not often implemented in standard Western forms of counselling and self-care. This included traditional songs, drumming, dancing, cedar work, medicine, and ways of seeing and knowing. This was purposefully done, as the model for the storytelling circle was built on research from Howell et al. (2015) which suggested incorporating traditional practices into care-models. As a community group of Indigenous youth, Elders, and leaders, we sought to answer the question of how we can blend the wellness methods of Indigenous knowledge framework and Western forms of counselling in a way that is respectful and holistic and brings balance to the four realms of the Medicine Wheel. These four realms include Spiritual Strength, Emotional Equilibrium, Physical Health, and Mental Health. During our discussions, we came up with the Youth Storytelling format. This was informed by the practices we already had in place, including a youth gathering twice a week and speaking with youth. It was agreed upon that having a flexible, comfortable, respectful, and fun space was needed to share our stories.

The process started with a photograph. We handed out disposable cameras to each member of the group and everyone came back the following week with a photo and a story to share. The stories did not just stop with the image. Members went on to talk about their families, their everyday lives, how they are doing in school, and their personal struggles. The photos served as a sort of ice-breaker to get down to the real stories they wanted to share. By sharing the pictures with the group, while sitting in a circular fashion, and by telling the stories related to a series of images, the group members began to develop personal narratives on their own lives in the community, while building upon the relationships around them. Each member of the group described their experiences the ways they knew how. This learning brought us all closer together, and not only did we see each other differently, but we also grew to know our culture differently, and with deeper meaning. Some participants such as myself did not have Indigenous oral history in our homes, so circle group was a way to learn about the lessons brought to us through stories. 


\section{Decolonizing Our Healing Practices: How Story Connects Us}

Each of us on this earth belongs to some sort of culture and relates to said culture to differing degrees. Our individual understandings of our identities come from our ancestors and are shaped by our environment (Iseke \& Moore, 2011). Some people may only be loosely connected to their culture, or it may be so crucial to the structure of their identity that their culture is echoed by their everyday acts and customs. Whatever the connection, our cultural identity can provide a sense of belonging (Wesley-Esquimaux \& Smolewski, 2004).

When stories are shared through generations, communities come together. In Swhaili, for example, there is a word "Ushahidi," meaning "testimony" (Rotich, 2017). This word is used to describe an apparatus to capture the truth of a community being collectively affected by an event. Using Ushahidi involves a wide variety of mediums, including written story, oral story, images, or materials to give a voice to a group (Rotich, 2017). The result is a beautiful entity large enough to inspire others to share their stories and even fight for change. Community building is nourished by story across cultures, and brings attention to the issues of the people. During Kenya's 2008 disputed presidential election, Ushahidi took place in an online storytelling format, which was used by citizens to map reports of violence and improve bottom-up forms of communication for marginalized groups (Rotich, 2017). This particular case may be used as a case study to examine the immediate actions that can be taken from sharing one's story.

Hulan and Eigenbrod (2008) have proclaimed that story is "the means by which knowledge is reproduced, preserved and conveyed from generation to generation ...oral traditions are the foundation of Aboriginal societies, connecting speaker and listener in communal experience and uniting past and present in memory" (p. 86). In addition to being a way to connect with others, sharing stories can facilitate the healing process for us and those around us through a collective sharing of experience (Stewart, 2008). Storytelling can help us learn about the tragic and comedic nature of life and make us feel less alone, confused, and anxious. The stories we share impact our life choices, emotional state, and relationships. The practices of mutual communication and harmonious storytelling are comprised of activities that use our interpersonal skills and build upon our resilience in the face of adversity. These practices allow us to reclaim our stories and take control of our voice (McCabe, 2007). Currently, Indigenous youth activists are using story, online platforms, and digital media to move change for Indigenous sovereignty. Protests for Wet'suwet'en at the British Columbia legislature building are being led by Indigenous youth activists, and these young people are leading the way for anti-pipeline protests and Indigeous rights demonstrations across the country. We are here, and we are using the tools of modern society to continue to connect to our culture and elevate our voices.

For many of us within the group, a sense of belonging to our Nation and newfound friends came from our weekly meetings. Group members described previous attempts at entering the spheres of traditional Western methods of healing, and how those experiences did not provide a secure connection to their wellbeing and the individual delivering the service. For example, youth described accessing services at a local clinic that did not take into account the unique relationship Indigenous Peoples have with counseling services and the world at large. Indigenous youth can be affected by news of injustices in our communities, or Murdered and Missing Indigenous Women and Girls (MMIWG). Clinicians should take historical context into account when working with Indigenous youth as their wellbeing will be dependent on understanding. But within our small group, hearing the stories of others around us brought a newfound strength. Learning of our past and the lessons our ancestors were taught through story showed us all that we are connected to everything and everyone on this sacred land, and that we can pull from that connection to access our collective vigour and resilience.

In my own case, as well as for others within the group, narrative identity was used as a healing tool. We began to deeply relate to our own culture through narrative, and just as we learned about Indigenous cultures, including Stó:lō, Cree, Algonquin, and Mi'kmaq, thus we shared stories from friends, including 
those from Latin America, India, Egypt, and Hawaii. We became connected to our local Elders and healers, asking them questions and feeling comfortable gaining guidance. A community was formed through the weekly group meetings as we all shared a journey of gaining knowledge and strengthening our identities through story.

The experience given from the Youth Storytelling Circle indicates the need for treatment interventions that work to celebrate and recognize the importance of Indigenous Peoples and the broad historical context in which these communities live. Recommendations from researchers, academics, Elders, community leaders, and storytellers support the need to improve the healing and treatment for Indigenous populations suffering from the effects of historical trauma and oppression, addictions, abuse, and other effects (Kirmayer, Brass, \& Trait, 2000). The findings also align with Howell and Yuille's (2004) study, which confirmed the value of community and identity for Indigenous Peoples living in a modern urban environment and their passage to attaining safe traditional wellness care.

\section{Conclusion}

Story reflects the internal and environmental setting that an individual grows up in, and how they choose to incorporate the events of their lives into a narrative. Each of us weaves multiple factors of the self together to add purpose, as one would with the smooth surface of cedar to create a basket. The complex nature of one's personal narrative forms a lasting centre for identity and can take the form of a story, free to be expressed in whatever way one would like (Mohammed, 2018). A life story expresses the importance of events, and how that event impacts the life of the person involved. This expression of an individual story and its importance was showcased in the storytelling process within the circle, as youth shared personal experiences in narrative form.

The cornerstone of our healing within the circle was the connection to the community because in learning about our culture, we were able to find the belonging that supported us to move through our trauma safely. Auger, Howell, and Gom (2016) tell us that when culturally meaningful procedures are implemented for Indigenous Peoples, their health will improve. From our experience within the circle, we know this to be true. There will always be a place for youth to gather and share their stories because of the compassionate work we all continue to do for local Nations in the Fraser Valley. I hope the method of storytelling circles will one day be implemented for youth and adults alike in public institutions such as colleges, universities, community centres, and workplaces. Storytelling as healing is no longer a holistic approach untouched by conventional healing methods; it can be incorporated in our daily lives through the knowledge of our Indigenous ancestors. When communities listen to youth and give them the space to dream, lead, and act, the outcome is outstanding. Identities are strengthened, communities are brought together, and lives are transformed by the simple act of sharing one's story. 
The Arbutus Review $\bullet 2020 \bullet$ Vol. 11, No. 1 Special Issue on Indigenous Wellness •

https://doi.org/10.18357/tar111202019324

\section{References}

Archibald, J. A. (2008). Indigenous storywork: Educating the heart, mind, body, and spirit. Vancouver, BC: UBC Press.

Auger, M., Howell, T., \& Gomes, T. (2016). Moving toward holistic wellness, empowerment, and selfdetermination for Indigenous peoples in Canada: Can traditional Indigenous healthcare practices increase ownership over health and healthcare decisions? Canadian Journal of Public Health, 107(4-5), e393-e398. https://doi.org/10.17269/CJPH.107.5366

Beltrán, R., \& Begun, S. (2014). 'It is medicine': Narratives of healing from the Aotearoa. Digital Storytelling as an Indigenous Media Project (ADSIMP). Psychology and Developing Societies, 26(2), 155-179. https://doi.org/10.1177/0971333614549137

Bernette, C. E, \& Figley, R. C, (2017). Historical oppression, resilience, and transcendence: Can a holistic framework help explain violence experienced by Indigenous People? Social Work, 62(1), 37-44. https://doi.org/10.1093/sw/sww065

Chandler, M. J., \& Lalonde, C. (1998). Cultural continuity as a hedge against suicide in Canada's First Nations. Transcultural psychiatry, 35(2), 191-219. https://doi.org/10.1177/136346159803500202

Corntassel, J., Chaw-win-is, \& T'lakwadzi (2009). Indigenous storytelling, truth-telling, and community approaches to reconciliation. ESC: English Studies in Canada, 35(1), 137-159. https://doi:10.1353 lesc. 0.0163

Chansonneuve, D. (2005). Reclaiming connections: Understanding residential school trauma among Aboriginal people. Aboriginal Healing Foundation.

George, D. (1974). If the legends fall silent. In My heart soars. Hancock House.

Gone, J. P. (2013). Redressing First Nations historical trauma: Theorizing mechanisms for Indigenous culture as a mental health treatment. Transcultural Psychiatry, 50(5), 683-706. https://doi: $10.1177 / 1363461513487669$

Homicide in Canada (2014). Canadian Centre for Justice Statistics (Released November 25, 2015). Ottawa, ON: Statistics Canada.

Howell, T., Auger, M., Gomes, T., Brown, F. L., \& Leon, A. Y. (2015). Sharing our wisdom: A holistic Aboriginal health initiative. International Journal of Indigenous Health, 11(1), 111-132. https://doi.org/10.18357/ijih111201616015

Howell, T. M., \& Yuille, J. C. (2004). Healing and treatment of Aboriginal offenders: A Canadian example. American Journal of Forensic Psychology, 22, 53-76.

Hulan, R., \& Eigenbrod, R. (2008). Aboriginal oral traditions: Theory, practice, ethics. Fernwood Publishing.

Iseke, J., \& Moore, S. (2011). Community-based Indigenous digital storytelling with elders and youth. American Indian Culture and Research Journal, 35(4), 19-38. https://doi.org/10.17953/aicr.35.4. 4588445552858866

Iseke, J. (2013). Indigenous storytelling as research. International Review of Qualitative Research, 6(4), 559-577. https://doi.org/10.1525/irqr.2013.6.4.559

Joe, R. (1989). I lost my talk. In P. Monture and P. McGuire (Eds.), First voices: An Aboriginal women's reader (p. 129). Toronto, ON: Inanna Publications and Education.

Kirmayer, J. L., Brass, M. J., \& Trait, C. L., (2000). The mental health of Aboriginal peoples: Transformations of identity and community. The Canadian Journal of Psychiatry, 45(7), 607-616. https://doi.org/10.1177/070674370004500702

Kirmayer, L., Simpson, C. \& Cargo, M. (2003). Healing traditions: Culture, community, and mental health promotion with Canadian Aboriginal peoples. Australasian Psychiatry, 11(sup1), S15S23. https://doi.org/10.1046/j.1038-5282.2003.02010.x 
The Arbutus Review • $2020 \bullet$ Vol. 11, No. 1 Special Issue on Indigenous Wellness •

https://doi.org/10.18357/tar111202019324

McCabe, G. H. (2007). The healing path: A culture and community derived Indigenous therapy model. Psychotherapy: Theory, Research, Practice, Training, 44(2), 148-160. https://doi.org/10.1037/ 0033-3204.44.2.148

Mohammed, F. (2018, August 3). How storytelling heals. JSTOR Daily. https://daily.jstor.org/howstorytelling-heals/

O'Keefe, V. M., Tucker, R. P., Cole, A. B., Hollingsworth, D. W., \& Wingate, L. R. (2018). Understanding Indigenous suicide through a theoretical lens: A review of general, culturally-based, and Indigenous frameworks. Transcultural Psychiatry, 55(6), 775-799. https://doi.org/10.1177/1363461518 778937

Rotich, J. (2017). Ushahidi: Empowering citizens through crowdsourcing and digital data collection. The Journal of Field Actions: Field Actions Science Reports, (Special Issue 16), 36-38.

Stewart, S. L. (2008). Promoting Indigenous mental health: Cultural perspectives on healing from Native counsellors in Canada. International Journal of Health Promotion and Education, 46(2), 49-56. https://doi.org/10.1080/14635240.2008.10708129

Waldram, J. (Ed.). (2008). Aboriginal healing in Canada: studies in therapeutic meaning and practice. Ottawa: Aboriginal Healing Foundation.

Ward, C., Branch, C., \& Fridkin, A. (2016). What is Indigenous cultural safety - and why should I care about it. Visions Journal, 11(4), 29.

Wesley-Esquimaux, C. C., \& Smolewski, M. (2004). Historic trauma and Aboriginal healing. The Aboriginal Healing Foundation Research Series. Ottawa: Aboriginal Healing Foundation. http://www.ahf. ca/downloads/historic-trauma.pdf

Wexler, L. (2009). The importance of identity, history, and culture in the wellbeing of Indigenous youth. The Journal of the History of Childhood and Youth, 2(2), 267-276. https://doi.org/10.1353/hcy.0. 0055

Witt, N. (1998). Promoting self-esteem, defining culture. Canadian Journal of Native Education. 22(2), 260-273. 